\title{
Enthesitis: an obscured extraintestinal manifestation in pediatric inflammatory bowel disease
}

\author{
Nelgin Gerenli ${ }^{1 \oplus}$, Betül Sözeri' ${ }^{2 \oplus}$ \\ Departments of ${ }^{1}$ Pediatric Gastroenterology and ${ }^{2}$ Pediatric Rheumatology, University of Health Sciences, Ümraniye Training and \\ Research Hospital, Istanbul, Turkey.
}

\begin{abstract}
Background. Enthesitis is an extra-intestinal manifestation of inflammatory bowel disease (IBD) which often remains underdiagnosed in children. We aimed to evaluate the frequency of enthesitis in pediatric IBD patients using physical examination and ultrasound (US) assessment as the reference standard.

Methods. 31 children, 7 -18 years of age, diagnosed with IBD were recruited for a cross-sectional study. All subjects completed a study questionnaire and underwent both physical and US examination for the presence of the enthesitis.

Results. Of 31 subjects (17girls; median age 14(6) years) enrolled, 17 (55\%) had ulcerative colitis, 11 (35\%) had Crohn's disease, and $3(10 \%)$ had indeterminate colitis. The median time from IBD diagnosis was 1.2 years. At least one enthesitis (range 1-4) was identified in 14 (45\%) patients of whom nine had more than one enthesitis with symmetric involvement in eight. The quadriceps femoris insertion at the superior portion of the patella was the frequently involved site (32\%, 9 of 28 sites), followed by patellar ligament insertion at tibial tuberositas. The presence of enthesitis was associated with a higher intensity of the musculoskeletal pain ( $\mathrm{p}=0.018)$, but physical activity remained unaffected $(\mathrm{p}=0.056)$.

Conclusions. Enthesitis is a common underestimated extra-intestinal manifestation of IBD that may impact the musculoskeletal health of children. Future studies with more extensive cohorts are needed to evaluate enthesial involvement both with physical examination and US in order to predict the long-term outcomes of the enthesitis on children with IBD.
\end{abstract}

Key words: pediatric inflammatory bowel disease, extraintestinal manifestations, enthesitis.

Inflammatory bowel disease (IBD) refers to a group of chronic inflammatory disorders affecting the gastrointestinal tract, which may be associated with extraintestinal manifestations involving the eyes, skin, hepatobiliary and musculoskeletal systems. ${ }^{1} \quad$ Musculoskeletal involvement, affecting especially the peripheral or axial joints, can precede, concur, or succeed IBD. Enthesitis which is an inflammation at the insertion site of the ligaments or tendons to the bone is a sign of musculoskeletal involvement. ${ }^{2,3}$ It is a distinct clinical hallmark

$凶$ Nelgin Gerenli

nelgingerenli@gmail.com

Received 17th July 2020, revised 18th November 2020, 26th December 2020, accepted 29th December 2020. of spondyloarthropathies (SpA) in both children and adults, observed also in healthy children ${ }^{4}$ as well as in children with juvenile idiopathic arthritis (JIA), particularly those with enthesitis-related arthritis (ERA). ${ }^{5,6}$ Articularperipheral complications occur in $23 \%$, and axial involvement in $4 \%$ of adult patients with IBD. ${ }^{7,8}$ Data are limited in children. One study that evaluated children with IBD-associated arthropathy found enthesitis and sacroiliitis (SI) in $7 \%$ and $25 \%$ of patients, respectively. ${ }^{9}$ The pathophysiology of enthesitis includes the innate and adaptive immunity with overlap of the interleukin (IL)-23 and IL-17 axis. The IL-23 is a key driver of enthesitis in rats and acts via previously unidentified $\mathrm{T}$ cells. ${ }^{10}$ Accordingly abnormal gut microbiome as seen in IBD 
patients may play a role in the emerging of entheseal pathology. ${ }^{11}$ Moreover, biomechanical factors such as obesity and physical activity may confound the pathogenesis of the enthesitis and might explain predominately lower limb distribution. ${ }^{12}$ Enthesitis is generally independent of IBD activity index, and may be asymptomatic in the majority of patients. ${ }^{13,14}$ Children with IBD are usually not examined for enthesitis and additionally there is no standard protocol for such examination. Yet, clinical findings including localized pain, tenderness, and swelling are suggestive of enthesitis..$^{15}$ If left untreated, enthesitis may cause osteopenia, erosions, soft tissue calcifications, and new bone formation. Osteopenia, which is present in many patients with IBD, may also aggravate enthesitis. ${ }^{16}$ Ultrasonography (US) and power Doppler ultrasonography (PDUS) are used for the diagnosis of inflammatory enthesitis. ${ }^{17}$ This study aimed to investigate the frequency of enthesitis in children with IBD.

\section{Material and Methods}

The study included 31 children, 7 to 18 years of age, who had been diagnosed with Crohn's disease (CD), ulcerative colitis (UC), or indeterminate colitis (IC), at the Pediatric Gastroenterology Unit. The trial was approved by the University of Health Sciences Umraniye Research and Training Hospital Ethics Committee (approval number 19/12/201926670).

Inclusion was made regardless of the duration, phenotype, severity or current activity of the disease and all patients had been on 5 amino salicylic acid (5-ASA) and azathioprine treatment, with or without low dose of methylprednisolone. Disease activity indexes for CD and UC or IC were calculated using the Pediatric Cohn's Disease Activity Index (PCDAI) and the Pediatric Ulcerative Colitis Activity Index (PUCAI), respectively. ${ }^{18,19}$ Disease phenotype at diagnosis was categorized according to the Paris classification. ${ }^{20}$ All IBD patients were evaluated for coexistence of familial Mediterranean fever (FMF), using FMF diagnostic criteria. ${ }^{21,22}$ Clinical information about previous diagnoses, anthropometric measurements and laboratory tests (albumin, C-reactive protein (CRP), complete blood count (CBC), and erythrocyte sedimentation rate (ESR)) were obtained from the hospital's medical record system. Informed consent was taken from the parents and children prior to inclusion. Patients who had been previously diagnosed with arthritis or SpA, had overuse tendinitis, were on non-steroidal antiinflammatory drugs or were unable to describe pain accurately were excluded.

Initially, a questionnaire was given to the parents or the children themselves for demographic and historical characteristics and the presence or absence of musculoskeletal pain, joint symptoms and the degree of the daily physical activity. The level of the sportive activities done by the children was also detailed to exclude overuse tendinitis. Musculoskeletal pain intensity within the previous month was designed to range from 0 (no pain) to 10 (intense pain) using numerical pain rating scale (NPRS). ${ }^{23,24}$ Physical activity score ranged from 0 (not active) to 5 (very active). ${ }^{25}$

Musculoskeletal examination: The subjects were examined by the same pediatric rheumatologist who was blinded to the diagnosis of the disease phenotype and clinical history of the patients including musculoskeletal symptoms and medications. The patients were also examined for signs suggesting spondyloarthropathies as well as peripheral extraintestinal manifestations as dactylitis. Enthesitis was defined as the presence of tenderness on a vigorous tendon palpation. ${ }^{26} \mathrm{~A}$ standardized bilateral examination for enthesitis was performed, including the humeral supraspinatus insertion at the greater tuberosity, common flexor tendon insertion at the medial epicondyle, common extensor tendon insertion at the lateral epicondyle, hip extensor insertion at the greater trochanter, quadriceps femoris insertion at the superior patella, patellar ligament insertion at the patella and tibial tuberosity, Achilles tendon 
insertion at the calcaneus, and plantar fascial insertion at the calcaneus. ${ }^{27}$

Ultrasound (US) examination: Patients with signs of enthesitis were further evaluated by the same pediatric rheumatologist who was also experienced in musculoskeletal US examination (certified by EULAR, the European League Against Rheumatism). Philips IU22 US device with a high-frequency linear array $12 \mathrm{MHz}$ transducer was used. ${ }^{26,27}$ Grey-scale and power Doppler evaluation of each enthesial site in both longitudinal and transverse planes- included assessment of the abnormalities in the tendon appearance, hypoechogenicity, lack of normal fibrillar aspect, enthesophytes, bony erosions, bursitis and power Doppler signal at enthesis. Power Doppler imaging was standardized with a pulse repetition frequency of $500-750 \mathrm{~Hz}$ and gain adjusted to the highest level without background noise artefact. ${ }^{28,29}$ Enthesitis was graded according to its intensity: 0, absent; 1 , minimal (1 spot); 2, moderate (2 spots); and 3 , severe ( $\geq 3$ spots). ${ }^{5}$ Minimal power Doppler findings of enthesitis may be detected in normal children, thus findings of grade 2 or above were considered positive. ${ }^{6,30}$ Patients with and without enthesitis were compared. Entheses thickness [expressed in millimeters and defined with Balint cut-off for quadriceps $>6.1 \mathrm{~mm}$, inferior pole of patella (proximal rotuleus) and tibial tuberosity (distal rotuleus) $>4 \mathrm{~mm}$, Achilles $>5.29 \mathrm{~mm}$, plantar fascia $>4.4$ $\mathrm{mm}$ ] were recorded at each site and scored with US according to Glasgow Ultrasound Enthesitis Scoring System (GUESS), ranging from 0 to 36, which was validated by Balint et al. ${ }^{31,32}$

\section{Statistical analysis}

The results were analyzed by the Statistical Package for the Social Sciences (SPSS) version 11 for Windows (SPSS Inc.; Chicago, IL, USA). Shapiro-Wilks test was used to determine the distribution of the variables. Independent samples t-test was used for comparison of normally distributed variables and the results were shown as mean and standard deviation (SD). Mann-Whitney U test was used for non- normally distributed variables and the results were shown as interquartile range (IQR). Pearson correlation test, Fisher's exact test, and chi-square test were used to compare the absence or presence of enthesitis and $p$ values of less than 0.05 were accepted as significant.

\section{Results}

The study included 31 children with a female to male ratio of 1.2 (F/M: 17/14). The median (IQR) age of the study population was 14 (6) years. Of 31 children, 17 (55\%) had UC, 11 (35\%) had CD, and $3(10 \%)$ had indeterminate colitis (IC). The median (IQR) time from IBD diagnosis was 8 (6) months and all patients were receiving one or more medication (Table I). Pediatric disease activity index and bowel involvement are listed in Table I. All IBD patients had negative p-ANCA results and none had coexisting FMF disease. There was no relationship between enthesitis and clinical variables, including IBD phenotype, IBD activity index and levels of inflammatory markers. However, patients with enthesitis had younger age $(p=0.048)$, and higher body mass index SDS (BMI SDS) $(\mathrm{p}=0.041)$, compared to those with no entheseal involvement (Table II). Musculoskeletal pain intensity score within the previous month ranged from 1 (no pain) to 10 (severe intense pain) points. Children, having at least one enthesitis reported a greater intensity of pain than those without enthesitis $(p=0.001)$. The level of physical activity was not found to be affected by the presence of pain or enthesitis $(p=0.066)$. The results of blood tests obtained at the time of examination are summarized in Table II. A total of 28 inflamed entheseal sites were detected in 14 of 31 (45\%) patients. Nine $(64 \%)$ of the 14 patients with enthesitis had more than one tender enthesis (range 1-4), with symmetric involvement in eight $(57 \%)$ of them. Only one patient with IC had entheseal involvement. The most common sites of enthesitis were the quadriceps femoris insertion at the superior portion of the patella (9 of 28 sites), patellar ligament insertion at tibial tuberositas (7 of 28 sites) and the Achilles tendon insertion at the calcaneus (7 of 28 
Table I. Demographic and clinical characteristics of children with inflammatory bowel disease.

\begin{tabular}{|c|c|c|c|c|}
\hline Characteristics & All $(\mathrm{N}=31)$ & $\begin{array}{l}\text { Ulcerative colitis } \\
\qquad(\mathrm{N}=17)\end{array}$ & $\begin{array}{l}\text { Crohn's disease } \\
\qquad(\mathrm{N}=11)\end{array}$ & $\begin{array}{c}\text { Indeterminate } \\
\text { colitis }(\mathrm{N}=3)\end{array}$ \\
\hline Age (years), median (IQR) & $14(6)$ & $15(6)$ & $14(6)$ & $9(0)$ \\
\hline Disease duration (months), median (IQR) & $8(6)$ & $6(6)$ & $11(17)$ & $6(15)$ \\
\hline \multicolumn{5}{|l|}{ Disease location, n (\%) } \\
\hline Rectosigmoid & $5(16 \%)$ & $3(18 \%)$ & & $2(67 \%)$ \\
\hline Left sided disease & $5(16 \%)$ & $4(24 \%)$ & & $1(33 \%)$ \\
\hline Pancolitis & $10(33 \%)$ & $10(59 \%)$ & & \\
\hline Large intestine only & $21(68 \%)$ & $17(100 \%)$ & $1(9 \%)$ & $3(100 \%)$ \\
\hline Small intestine only & $1(3 \%)$ & & $1(9 \%)$ & \\
\hline Small and large intestine & $9(29 \%)$ & & $9(82 \%)$ & \\
\hline \multicolumn{5}{|l|}{ Medications, n (\%) } \\
\hline 5-Acetylsalicylic acid & $31(100 \%)$ & $17(100 \%)$ & $11(100 \%)$ & $3(100 \%)$ \\
\hline Azathioprine & $28(90 \%)$ & $17(100 \%)$ & $11(100 \%)$ & $0(0 \%)$ \\
\hline Methylprednisolone & $4(13 \%)$ & $0(0 \%)$ & $4(36 \%)$ & $0(0 \%)$ \\
\hline
\end{tabular}

sites). The least affected ligament was the hip extensor insertion at greater trochanter (Table III). The most frequently observed entheseal pathology on ultrasonographic examination was thickening of tendon $12(38 \%)$ followed by peritendenous edema $10(31 \%)$, hypoecogenisity $6(19 \%)$, loss of thickness $2(6 \%)$ and increased Doppler signal (6\%). No tendon tears, intratendinous calcifications, enthesophytes or bone erosions were observed (Table IV). Bursitis was detected in four patients, three with bilateral retrocalcaneal and one with bilateral infrapatellar involvement. The treatment for enthesitis was arranged as sulfasalazine or ibuprofen for mild cases (9 patients), methylprednisolone dosage adjustment for moderate ( 2 patients) and in three patients with severe disease the treatment was switched to anti-TNF agent (infliximab).

\section{Discussion}

The present study reports the frequency of enthesitis in children with IBD, which to our knowledge is the first pediatric study investigating ultrasound-guided diagnosis of enthesitis. As far as we could find in the literature, only one study reported enthesitis in pediatric IBD patients with diagnosis based solely on physical examination findings, ${ }^{33}$ another study reported enthesitis in a study investigating spondyloarthropathies in pediatric IBD. ${ }^{9}$ The rate of enthesitis in pediatric IBD study was $21 \%$, where $12 \%$ of the subjects had 3 or more tender enthuses. ${ }^{33}$

Compared with previous studies, the frequency of enthesitis in patients with IBD was higher in our study, with at least one ultrasonografically verified enthesitis in $45 \%$ of all patients. This was thought to be due to the diagnostic approach using both physical examination and US. This was similar to adult IBD studies in which both physical and US examinations had been performed and the frequencies had been reported to be between $44.3-84.1 \%$. ${ }^{34,35}$ In a meta-analysis performed for the prevalence of the axial and peripheral manifestation in adults with $\mathrm{CD}$ and $\mathrm{UC}$, the prevalence of the peripheral manifestations such as enthesitis was reported to range between $1-54 \%{ }^{36}$

Jousse-Joulin et al. ${ }^{5}$ found that entheseal tenderness does not always correspond to ultrasound abnormalities while radiographic enthesitis is also not associated with positive physical examination findings, suggesting subclinical enthesitis. In accordance, a 
Table II. Comparison of clinical features, musculoskeletal pain and activity levels between patients with and without enthesitis.

\begin{tabular}{|c|c|c|c|}
\hline Features & No enthesitis $(\mathrm{N}=17)$ & Enthesitis (N=14) & p-value \\
\hline Age (years), median (IQR) & $16(6)$ & $11(6)$ & 0.048 \\
\hline Gender, n (\%) & & & 0.015 \\
\hline Male & $9(53 \%)$ & $5(36 \%)$ & \\
\hline Female & $8(47 \%)$ & $9(64 \%)$ & \\
\hline $\mathrm{BMI}$ SDS, mean \pm SD & $-0.57 \pm 1.4$ & $0.19 \pm 0.79$ & 0.041 \\
\hline Disease duration (months), median (IQR) & $9(17)$ & $6(6)$ & 0.570 \\
\hline \multicolumn{4}{|l|}{ Inflammatory bowel disease type, $\mathrm{n}(\%)$} \\
\hline Crohn's disease & $5(29 \%)$ & $6(43 \%)$ & 0.715 \\
\hline Ulcerative colitis & $10(59 \%)$ & $7(50 \%)$ & 0.480 \\
\hline Indeterminate colitis & $2(12 \%)$ & $1(7 \%)$ & - \\
\hline \multicolumn{4}{|l|}{$\begin{array}{l}\text { Pediatric Activity Index (PCAI or PUCAI), median } \\
\text { (IQR) }\end{array}$} \\
\hline Crohn's disease (PCDAI) & $20.0(25.0)$ & $30.0(5.0)$ & 0.452 \\
\hline Ulcerative colitis (PUCAI) & $20.0(1.25)$ & $20.0(10.0)$ & 0.229 \\
\hline Inflammatory bowel disease activity, $\mathrm{n}(\%)$ & & & 0.778 \\
\hline Remission & $7(33 \%)$ & $6(38 \%)$ & \\
\hline Mild to moderate disease & $10(67 \%)$ & $8(62 \%)$ & \\
\hline $\begin{array}{l}\text { Musculoskeletal pain score during last one month, } \\
\text { median (IQR) }\end{array}$ & $3.0(4.5)$ & $7.0(3.25)$ & 0.001 \\
\hline Physical activity level, n (\%) & & & 0.066 \\
\hline Not active & $0(0 \%)$ & $0(0 \%)$ & \\
\hline A little active & $0(0 \%)$ & $0(0 \%)$ & \\
\hline Regular activity & $0(0 \%)$ & $1(7 \%)$ & \\
\hline Pretty active & $3(17 \%)$ & $5(36 \%)$ & \\
\hline Very active & $14(83 \%)$ & $8(57 \%)$ & \\
\hline \multicolumn{4}{|l|}{ Laboratory, median (IQR) } \\
\hline $\mathrm{WBC}\left(x 10^{3} / \mu \mathrm{l}\right)$ & $9.31(2.9)$ & $8.6(4.4)$ & 0.894 \\
\hline Hemoglobin (gr/dl) & $12.6(1.1)$ & $12.5(1.85)$ & 0.116 \\
\hline Platelets $\left(\times 10^{3} / \mu \mathrm{l}\right)$ & $346(103)$ & $352(116)$ & 0.642 \\
\hline Albumin (gr/dl) & $4.1(0.4)$ & $3.9(0.3)$ & 0.226 \\
\hline $\operatorname{ESR}(\mathrm{mm} / \mathrm{h})$ & $16(10)$ & $28(13)$ & 0.673 \\
\hline CRP (mg/L) & $0.2(0.1)$ & $0.4(0.5)$ & 0.370 \\
\hline
\end{tabular}

BMI SDS: body mass index standard deviation score, CRP: C-reactive protein, ESR: erythrocyte sedimentation rate, IQR: interquartile range, PCDAI: Pediatric Crohn's Disease Activity Index, PUCAI: Pediatric Ulcerative Colitis Activity Index, WBC: white blood cell

research in adult IBD patients without any musculoskeletal symptoms showed that a majority of the subjects had ultrasonographic findings suggestive of enthesitis, not observed in controls. ${ }^{37}$ This trial supports the hypothesis that enthesitis is prevalent and asymptomatic in patients with IBD. Of note, compared with clinical examination US is a more sensitive method in detecting enthesitis. In a recent study, US detected enthesitis in 25 of 30 patients whereas clinical enthesitis was seen only in 15 of them. ${ }^{6}$ Similar results had been reported in studies on concomitance of psoriasis and enthesitis, emphasizing that US is a valuable 
Table III. Distribution of enthesitis among ligaments of lower limbs in children with inflammatory bowel disease ( $\mathrm{N}=28$ sites).

\begin{tabular}{lllc}
\hline Enthesitis & Left & Right & Bilateral \\
\hline Hip extensor insertion at greater trochanter, n (\%) & & $1(4 \%)$ & \\
Quadriceps femoris insertion at superior portion of patella, n (\%) & $1(4 \%)$ & $2(7 \%)$ & $6(21 \%)$ \\
Patellar ligament insertion at tibial tuberositas, n(\%) & $1(4 \%)$ & $2(7 \%)$ & $4(14 \%)$ \\
Plantar fascial insertion at the calcaneus, n (\%) & & $2(7 \%)$ & $2(7 \%)$ \\
Achilles tendon insertion at calcaneus, n (\%) & $1(4 \%)$ & $2(7 \%)$ & $4(14 \%)$ \\
\hline
\end{tabular}

Table IV. Observed entheseal pathologies and involved sites.

\begin{tabular}{|c|c|c|c|c|c|}
\hline \multirow[b]{2}{*}{ Entheseal pathology } & \multicolumn{5}{|c|}{ Involved sites } \\
\hline & $\begin{array}{l}\text { Hip extensor } \\
\text { insertion at } \\
\text { the greater } \\
\text { trochanter }\end{array}$ & $\begin{array}{l}\text { Quadriceps femoris } \\
\text { insertion at the } \\
\text { superior portion of } \\
\text { patella }\end{array}$ & $\begin{array}{l}\text { Patellar ligament } \\
\text { insertion at the } \\
\text { tibial tuberositas }\end{array}$ & $\begin{array}{c}\text { Achilles } \\
\text { tendon } \\
\text { and fascia }\end{array}$ & $\begin{array}{c}\text { Plantar } \\
\text { fascia }\end{array}$ \\
\hline Thickening of tendon $(\mathrm{n}=12)$ & 1 & 4 & 2 & 4 & 1 \\
\hline Hypoechogenicity of tendon $(n=6)$ & & 3 & 1 & 1 & 1 \\
\hline Peritendinous edema $(n=10)$ & & 3 & 2 & 5 & \\
\hline Doppler signal (n=2) & & & 1 & 1 & \\
\hline Loss of thickness $(n=2)$ & & 1 & & & 1 \\
\hline
\end{tabular}

examination tool. ${ }^{38-41}$ The introduction of power Doppler increased the sensitivity, allowing visualization of abnormal vascularisation and hyperemia of the soft tissue. ${ }^{41,42}$

The current study also revealed that patients with increased BMI had statistically higher entheseal involvement, which had not been previously reported in pediatric patients with IBD. Similar data had been reported in several adult studies especially in patients with psoriasis related enthesitis where the increased BMI was found to be correlated with entheseal involvement. ${ }^{36,37}$ The authors supposed that the increased BMI may have burdened ligaments of lower extremities. ${ }^{38,44}$

The frequency of enthesitis was found to be almost equal in both UC and CD, similar with recent trials which reported that concurrence of enthesitis was not different among patients with UC or CD. ${ }^{33-36}$ Nevertheless patients with entheseal involvement had relatively younger age $(p=0.048)$ with female predominance $(p=0.015)$. Horton et al. ${ }^{33}$ showed that there was no age and sex differences in patients with enthesitis, however Jose et al..$^{55}$ showed that extra-intestinal manifestations had been observed more frequently in girls with IBD. A female predominance of enthesial involvement was also found in studies performed on patients with psoriasis..$^{37,41}$

Familial Mediterranean fever and inflammatory bowel disease association was reported in many studies. The prevalence of FMF in Turkish children with IBD was found to range between $15-21.2 \%{ }^{42,43}$ Children with $\mathrm{CD}$ had increased FMF prevalence, whereas in UC the rate was found to be similar with Turkish healthy controls. ${ }^{42,43}$ When patients with FMF were investigated for the presence of IBD a concomitant IBD was diagnosed in $15.4 \%$ of them. ${ }^{44}$ Interestingly Yurtcu et al. ${ }^{45}$ did not find an association between FMF gene mutations and IBD phenotypic characteristics, but IBD patients without Mediterranean fever (MEFV) mutations had a statistically significant increase in extraintestinal disease frequencies. As enthesitis is also prevalent among patients with severe $\mathrm{FMF}^{46}$ it is important to exclude FMF concurrence in children with IBD, however none 
of our patients met the diagnostic criteria of FMF, hence we did not perform FMF mutation analysis.

Quadriceps femoris insertion at superior portion of patella was the most affected entheseal site, similar to the results of Weiss et al. ${ }^{17}$ who showed that $30 \%$ of enthesitis-related arthritis in pediatric patients was at the quadriceps insertion of superior patella, followed by common extensor (12\%) and Achilles (10\%) tendons. Nevertheless, Cantini at al..$^{34}$ reported that the Achilles' tendon had been mostly affected, followed by proximal and distal insertions of the patellar tendons. According to other trials the patellar tendon insertion at the tibial tuberosity was affected mostly. ${ }^{6,47-49}$ In our trial, increased tendon thickness was the most commonly detected finding which was consistent with most previous studies. ${ }^{50,51}$ These results would help understand the differences in entheseal involvement between pediatric and adult patients, and as well as the differences between concurrent diseases.

The patients with enthesitis were more likely to have increased musculoskeletal pain than those without enthesitis. ${ }^{33,51}$ In the current study the enthesitis was detected in patients who had more intensive pain within the previous month $(p=0.001)$. Horton et al. ${ }^{33}$ supposed that presence of enthesitis may reflect an inflammatory process which may cause pain or patients with enthesitis could have lower pain thresholds, or a combination of the two. The other hypothesis is that undertreated enthesitis could predispose affected individuals to experience more pain elsewhere. ${ }^{33}$ The study of healthy school children showed that those with enthesitis reported tenderness at control sites at lower applied pressures. ${ }^{52}$

Even so, the presence of enthesitis did not seem to affect the level of activity in our patients. Horton et al. ${ }^{33}$ also reported that the presence of enthesitis did not affect the level of activity in children with IBD. Palm et al. ${ }^{53}$ investigated physical activity and quality of life in adult IBD patients with non-inflammatory joint pain
(NIJP) and reported that NIJP could decrease physical activity and quality of life in these subjects. Accordingly a study on enthesitis and quality of life in patients with juvenile rheumatoid arthritis showed a marked decrease in both physical activity and quality of life. ${ }^{54}$ The issue could be explained by the fact that these subjects had associated co-morbidities like arthritis. Further studies will provide a better understanding of these issues.

Enthesitis is responsive to treatment, but it is unclear, beyond pain relief, if the response translates to true resolution and reversal of the underlying morphological destruction. ${ }^{56}$ There is no specified therapy for enthesitis in children with IBD, but treatment for JIA, psoriasis and SpA associated enthesitis is broadly discused..$^{56-58}$ The first line of choice for active enthesitis are non-steroidal antiinflammatory drugs (NSAIDs), whereas in severe active enthesitis, American College of Rheumatology/Arthritis recommends using anti-TNF, anti-IL-17 agents and Janus kinase inhibitors. In children and adolescents with chronic active enthesitis unresponsive to NSAIDs, the bridging therapy with an oral glucocorticoids are recommended. ${ }^{58}$ In our case, the treatment was tailored as sulfasalazine or ibuprofen for mild enthesitis, whereas for those with moderate disease the methylprednisolone was the choice and severe cases were switched to anti-TNF therapy.

The present study had a few limitations. First, the study was conducted with a limited number of patients. In addition, many of the drugs used to control IBD, including salicylate derivatives (used by all of our patients), cytotoxic medications such as azathioprine (used by 90\%) and oral steroids (used by $12 \%$ ), are also effective in the treatment of arthritis and enthesitis. This may interfere with the percentage of entheseal involvement. Moreover, we performed the study in a cohort of patients with a wellcontrolled disease. One could speculate that patients with more active intestinal disease and who are drug-free may have increased risk for other extraintestinal inflammatory conditions. 
Two or more entheseal examinations, first at the diagnosis and second at the time of remission, would most likely give more extensive information about the entheseal involvement and response to treatment in children with IBD.

In conclusion, this trial supports the hypothesis that enthesitis is a prevalent extraintestinal manifestation of IBD regardless of the type of disease. The concurrence of enthesitis causing subclinical sign and symptoms may have impacts on musculoskeletal health of pediatric patients with IBD. A higher BMI could contribute to entheseal involvement, especially in lower extremities and aggravate the pain. Being different from adult IBD, children could have associated musculoskeletal pain which does not deteriorate their physical activity. To our knowledge, this is the first study using both physical examination and US to evaluate enthesitis in children with IBD. We supposed that powered Doppler evaluation is a more sensitive method to detect enthesitis, therefore, a combined clinical and US evaluation is probably the best approach to evaluate the presence of enthesitis in children with IBD. Further studies with more extensive cohorts are needed to evaluate the long-term impact of enthesitis in children with IBD.

\section{Author contribution}

The authors confirm contribution to the paper as follows: study conception and design: Nelgin Gerenli and Betül Sözeri, data collection: Nelgin Gerenli, analysis and interpretation of results: Nelgin Gerenli and Betül Sözeri, draft manuscript preparation: Nelgin Gerenli.

All authors reviewed the results and approved the final version of the manuscript.

\section{Ethical approval}

The trial was approved by the University of Health Sciences Umraniye Research and Training Hospital Ethics Committee (approval number 19/12/2019-26670).

\section{Source of funding}

There has been no funding obtained for this work.

\section{Conflicts of interest}

We declare no conflicts of interest associated with this publication.

\section{REFERENCES}

1. Mamula P, Markowitz JE, Baldassano RN. Inflammatory bowel disease in early childhood and adolescence: special considerations. Gastroenterol Clin North Am 2003; 32: 967-995.

2. Das KM. Relationship of extraintestinal involvements in inflammatory bowel disease: new insights into autoimmune pathogenesis. Dig Dis Sci 1999; 44: 1-13.

3. Watad A, Cuthbert RJ, Amital H, McGonagle D. Enthesitis: much more than focal insertion point inflammation. Curr Rheumatol Rep 2018; 20: 41.

4. Chauvin NA, Ho-Fung V, Jaramillo D, Edgar JC, Weiss PF. Ultrasound of the joints and entheses in healthy children. Pediatr Radiol 2015; 45: 1344-1354.

5. Jousse-Joulin S, Breton S, Cangemi C, et al. Ultrasonography for detecting enthesitis in juvenile idiopathic arthritis. Arthritis Care Res (Hoboken) 2011; 63: 849-855.

6. Shenoy S, Aggarwal A. Sonologic enthesitis in children with enthesitis-related arthritis. Clin Exp Rheumatol 2016; 34: 143-147.

7. Sheth T, Pitchumoni CS, Das KM. Musculoskeletal manifestations in inflammatory bowel disease: a revisit in search of immunopathophysiological mechanisms. J Clin Gastroenterol 2014; 48: 308-317.

8. Fragoulis GE, Liava C, Daoussis D, Akriviadis E, Garyfallos A, Dimitroulas T. Inflammatory bowel diseases and spondyloarthropathies: from pathogenesis to treatment. World J Gastroenterol 2019; 25: 2162-2176.

9. Conti F, Borrelli O, Anania C, et al. Chronic intestinal inflammation and seronegative spondyloarthropathy in children. Dig Liver Dis 2005; 37: 761-767.

10. Sherlock JP, Joyce-Shaikh B, Turner SP, et al. IL-23 induces spondyloarthropathy by acting on ROR- $\gamma \mathrm{t}+$ CD3+CD4-CD8- entheseal resident T cells. Nat Med 2012; 18: 1069-1076. 
11. Kalinkovich A, Livshits G. A cross talk between dysbiosis and gut-associated immune system governs the development of inflammatory arthropathies. Semin Arthritis Rheum 2019; 49: 474484 .

12. Kaeley GS, Kaler JK. Peripheral enthesitis in spondyloarthritis: lessons from targeted treatments. Drugs 2020; 80: 1419-1441.

13. Dotson J, Crandall W, Bout-Tabaku S. Exploring the differential diagnosis of joint complaints in pediatric patients with inflammatory bowel disease. Curr Gastroenterol Rep 2011; 13: 271-278.

14. Jang HJ, Kang B, Choe BH. The difference in extraintestinal manifestations of inflammatory bowel disease for children and adults. Transl Pediatr 2019; 8: 4-15.

15. Rodríguez-Reyna TS, Martínez-Reyes C, YamamotoFurusho JK. Rheumatic manifestations of inflammatory bowel disease. World J Gastroenterol 2009; 15: 5517-5524.

16. Dotson JL, Hyams JS, Markowitz J, et al. Extraintestinal manifestations of pediatric inflammatory bowel disease and their relation to disease type and severity. J Pediatr Gastroenterol Nutr 2010; 51: 140-145.

17. Weiss PF, Chauvin NA, Klink AJ, et al. Detection of enthesitis in children with enthesitis-related arthritis: dolorimetry compared to ultrasonography. Arthritis Rheumatol 2014; 66: 218-227.

18. Kappelman MD, Crandall WV, Colletti RB, et al. Short pediatric Crohn's disease activity index for quality improvement and observational research. Inflamm Bowel Dis 2011; 17: 112-117.

19. Turner D, Hyams J, Markowitz J, et al; Pediatric IBD Collaborative Research Group. Appraisal of the pediatric ulcerative colitis activity index (PUCAI). Inflamm Bowel Dis 2009; 15: 1218-1223.

20. Levine A, Griffiths A, Markowitz J, et al. Pediatric modification of the Montreal classification for inflammatory bowel disease: the Paris classification. Inflamm Bowel Dis 2011; 17: 1314-1321.

21. Livneh A, Langevitz P, Zemer D, et al. Criteria for the diagnosis of familial Mediterranean fever. Arthritis Rheum 1997; 40: 1879-1885.

22. Gattorno M, Hofer M, Federici S, et al; Eurofever Registry and the Paediatric Rheumatology International Trials Organisation (PRINTO). Classification criteria for autoinflammatory recurrent fevers. Ann Rheum Dis 2019; 78: 10251032.

23. Kahl C, Cleland JA. Visual analogue scale, numeric pain rating scale and the McGill pain Questionnaire: an overview of psychometric properties. Physical Therapy Reviews 2005; 10: 123-128.
24. Williamson A, Hoggart B. Pain: a review of three commonly used pain rating scales. J Clin Nurs 2005; 14: 798-804.

25. Crocker PR, Bailey DA, Faulkner RA, Kowalski KC, McGrath R. Measuring general levels of physical activity: preliminary evidence for the Physical Activity Questionnaire for Older Children. Med Sci Sports Exerc 1997; 29: 1344-1349.

26. Eder L, Barzilai M, Peled N, Gladman DD, Zisman D. The use of ultrasound for the assessment of enthesitis in patients with spondyloarthritis. Clin Radiol 2013; 68: 219-223.

27. Kristensen S, Christensen JH, Schmidt EB, et al Assessment of enthesitis in patients with psoriatic arthritis using clinical examination and ultrasound. Muscles Ligaments Tendons J 2016; 6: 241-247.

28. Terslev L, Naredo E, Iagnocco A, et al; Outcome Measures in Rheumatology Ultrasound Task Force. Defining enthesitis in spondyloarthritis by ultrasound: results of a Delphi process and of a reliability reading exercise.Arthritis Care Res (Hoboken) 2014; 66: 741-748.

29. Gandjbakhch F, Terslev L, Joshua F, Wakefield RJ Naredo E, D'Agostino MA; OMERACT Ultrasound Task Force. Ultrasound in the evaluation of enthesitis: status and perspectives. Arthritis Res Ther 2011; 13: R188.

30. D'agostino MA, Aegerter P, Jousse-Joulin S, et al. How to evaluate and improve the reliability of power Doppler ultrasonography for assessing enthesitis in spondylarthritis. Arthritis Rheum 2009; 61: 61-69.

31. Balint PV, Kane D, Wilson H, McInnes IB, Sturrock RD. Ultrasonography of entheseal insertions in the lower limb in spondyloarthropathy. Ann Rheum Dis 2002; 61: 905-910.

32. Balint PV, Terslev L, Aegerter P, et al; OMERACT Ultrasound Task Force members. Reliability of a consensus-based ultrasound definition and scoring for enthesitis in spondyloarthritis and psoriatic arthritis: an OMERACT US initiative. Ann Rheum Dis 2018; 77: 1730-1735.

33. Horton DB, Sherry DD, Baldassano RN, Weiss PF. Enthesitis is an extraintestinal manifestation of Pediatric Inflammatory Bowel Disease. Ann Paediatr Rheumatol 2012; 1: 10.5455/apr.102920121510.

34. Cantini F, Niccoli L, Nannini C, et al. Case-control study on dactylitis, enthesitis, and anterior uveitis in spondyloarthritis associated with inflammatory bowel diseases: role of coexistent psoriasis. J Rheumatol 2017; 44: 1341-1346.

35. Rovisco J, Duarte C, Batticciotto A, et al. Hidden musculoskeletal involvement in inflammatory bowel disease: a multicenter ultrasound study. BMC Musculoskelet Disord 2016; 17: 84. 
36. Karreman MC, Luime JJ, Hazes JMW, Weel AEAM. The prevalence and incidence of axial and peripheral spondyloarthritis in inflammatory bowel disease: a systematic review and meta-analysis. J Crohns Colitis 2017; 11: 631-642.

37. Bandinelli F, Milla M, Genise S, et al. Ultrasound discloses entheseal involvement in inactive and low active inflammatory bowel disease without clinical signs and symptoms of spondyloarthropathy. Rheumatology (Oxford) 2011; 50: 1275-1279.

38. Moshrif A, Mosallam A, Mohamed EE, Gouda W, Doma M. Subclinical enthesopathy in patients with psoriasis and its association with other disease parameters: a power Doppler ultrasonographic study. Eur J Rheumatol 2017; 4: 24-28.

39. Kaeley GS, Eder L, Aydin SZ, Gutierrez M, Bakewell C. Enthesitis: a hallmark of psoriatic arthritis. Semin Arthritis Rheum 2018; 48: 35-43.

40. Zuliani F, Zabotti A, Errichetti E, et al. Ultrasonographic detection of subclinical enthesitis and synovitis: a possible stratification of psoriatic patients without clinical musculoskeletal involvement. Clin Exp Rheumatol 2019; 37: 593-599.

41. Gutierrez M, Filippucci E, De Angelis R, et al. Subclinical entheseal involvement in patients with psoriasis: an ultrasound study. Semin Arthritis Rheum 2011; 40: 407-412.

42. Uslu N, Yüce A, Demir H, et al. The association of inflammatory bowel disease and Mediterranean fever gene (MEFV) mutations in Turkish children. Dig Dis Sci 2010; 55: 3488-3494.

43. Yilmaz E, Ozen S, Balci B, et al. Mutation frequency of familial Mediterranean fever and evidence for a high carrier rate in the Turkish population. Eur J Hum Genet 2001; 9: 553-555.

44. Beşer OF, Kasapçopur O, Cokuğraş FC, Kutlu T, Arsoy N, Erkan T. Association of inflammatory bowel disease with familial Mediterranean fever in Turkish children. J Pediatr Gastroenterol Nutr 2013; 56: 498-502.

45. Yurtcu E, Gokcan H, Yilmaz U, Sahin FI. Detection of MEFV gene mutations in patients with inflammatory bowel disease. Genet Test Mol Biomarkers 2009; 13: 87-90.

46. Sen N, Yilmaz M, Mercan R, et al. Enthesitis may be one of the signs of severe disease in familial Mediterranean fever. Clin Rheumatol 2020; 40: 14791485.

47. D'Agostino MA, Said-Nahal R, Hacquard-Bouder C, Brasseur JL, Dougados M, Breban M. Assessment of peripheral enthesitis in the spondylarthropathies by ultrasonography combined with power Doppler: a cross-sectional study. Arthritis Rheum 2003; 48: 523533.
48. Gisondi P, Tinazzi I, El-Dalati G, et al. Lower limb enthesopathy in patients with psoriasis without clinical signs of arthropathy: a hospital-based casecontrol study. Ann Rheum Dis 2008; 67: 26-30.

49. Di Matteo A, Filippucci E, Cipolletta E, et al. Entheseal involvement in patients with systemic lupus erythematosus: an ultrasound study. Rheumatology (Oxford) 2018; 57: 1822-1829.

50. Atteno M, Costa L, Tortora R, et al. The occurrence of lower limb enthesopathy in coeliac disease patients without clinical signs of articular involvement. Rheumatology (Oxford) 2013; 52: 893-897.

51. Weiss PF, Klink AJ, Behrens EM, et al. Enthesitis in an inception cohort of enthesitis-related arthritis. Arthritis Care Res (Hoboken) 2011; 63: 1307-1312.

52. Sherry DD, Sapp LR. Enthesalgia in childhood: sitespecific tenderness in healthy subjects and in patients with seronegative enthesopathic arthropathy. J Rheumatol 2003; 30: 1335-1340.

53. Palm Ø, Bernklev T, Moum B, Gran JT. Noninflammatory joint pain in patients with inflammatory bowel disease is prevalent and has a significant impact on health related quality of life. J Rheumatol 2005; 32: 1755-1759.

54. Weiss PF, Beukelman T, Schanberg LE, Kimura Y, Colbert RA; CARRA Registry Investigators. Enthesitis-related arthritis is associated with higher pain intensity and poorer health status in comparison with other categories of juvenile idiopathic arthritis: the Childhood Arthritis and Rheumatology Research Alliance Registry. J Rheumatol 2012; 39: 2341-2351.

55. Jose FA, Garnett EA, Vittinghoff E, et al. Development of extraintestinal manifestations in pediatric patients with inflammatory bowel disease. Inflamm Bowel Dis 2009; 15: 63-68.

56. Kaeley GS, Kaler JK. Peripheral enthesitis in spondyloarthritis: lessons from targeted treatments. Drugs 2020; 80: 1419-1441.

57. Araujo EG, Englbrecht M, Hoepken S, et al. Effects of ustekinumab versus tumor necrosis factor inhibition on enthesitis: results from the enthesial clearance in psoriatic arthritis (ECLIPSA) study. Semin Arthritis Rheum 2019; 48: 632-637.

58. Ringold S, Angeles-Han ST, Beukelman T, et al. 2019 American College of Rheumatology/Arthritis Foundation Guideline for the Treatment of Juvenile Idiopathic Arthritis: Therapeutic Approaches for Non-Systemic Polyarthritis, Sacroiliitis, and Enthesitis. Arthritis Care Res (Hoboken) 2019; 71: 717-734. 